\title{
Ultrasonographic Screening and the Determination of Risk Factors involved in Developmental Dysplasia of the Hip
}

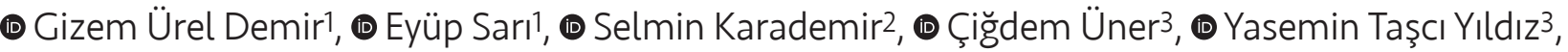 \\ (D) Ulaş Onay4, (1) Şenol Bekmez ${ }^{4}$ \\ 1Dr. Sami Ulus Obstetrics and Gynecology Children's Health and Disease Training and Research Hospital, Clinic of Pediatrics, Ankara, Turkey \\ 2Dr. Sami Ulus Obstetrics and Gynecology Children's Health and Disease Training and Research Hospital, Clinic of Pediatric Cardiology, Ankara, Turkey \\ ${ }^{3}$ Dr. Sami Ulus Obstetrics and Gynecology Children's Health and Disease Training and Research Hospital, Clinic of Radiology, Ankara, Turkey \\ ${ }^{4}$ Dr. Sami Ulus Obstetrics and Gynecology Children's Health and Disease Training and Research Hospital, Clinic of Orthopedics and Traumatology, \\ Ankara, Turkey
}

\begin{abstract}
Aim: Developmental dysplasia of the hip is an orthopedic problem which is a spectrum of disorders from the instability of the hip joint to total dislocation. Developmental dysplasia of the hip is frequently seen and has good prognosis when diagnosed and treated early. The aim of our study is to examine the risk factors leading to developmental dysplasia of the hip and to assess the value of hip ultrasonography.

Materials and Methods: In our research, 9.102 imagings of hip ultrasonography from 4.551 infants were analyzed retrospectively. One hundred and fifty-one infants who were diagnosed with developmental dysplasia of the hip and 170 healthy infants as a control group were compared in terms of birth order, being the firstborn, type of delivery, gestational age, birth weight, oligohydramnios, multiple pregnancy, breech presentation, swaddling, family history and existence of foot anomalies.

Results: Prematurity, oligohydramnios and a positive family history were observed to be significant risk factors for developmental dysplasia of the hip.

Conclusion: It is possible to prevent the complications and necessity of surgical treatment with early diagnosis. Therefore, we propose screening for developmental dysplasia of the hip for all infants.

Keywords: Developmental dysplasia of the hip, hip dislocation, hip dysplasia, hip instability, hip ultrasonography
\end{abstract}

\section{Introduction}

Developmental dysplasia of the hip (DDH) is defined as a disruption of the relationship between the acetabulum and the femoral head. The traditional term congenital hip dislocation, suggesting a pathology due to the prenatal malposition, has been replaced by the term DDH, as Klisic proposed, emphasizing the dynamic course of the disease (1).

The estimated incidence of hip instability during the newborn period ranges from $1 / 1.000$ to $3.4 / 100$, whereas

The manuscript has been presented in 4. Çocuk Dostları Congress as a poster (March 24-26,2016 istanbul).

\section{Address for Correspondence}

Gizem Ürel Demir MD, Dr Sami Ulus Obstetrics and Gynecology, Children's Health and Disease Training and Research Hospital, Clinic of Pediatrics, Ankara, Turkey Phone: +90 5052563688 E-mail: gizemurel@gmail.com ORCID: orcid.org/0000-0002-9928-3236

Received: 31.08 .2018 Accepted: 10.06.2019

${ }^{\circ}$ Copyright 2020 by Ege University Faculty of Medicine, Department of Pediatrics and Ege Children's Foundation The Journal of Pediatric Research, published by Galenos Publishing House. 
the prevalence of hip dislocation ranges from 1 to 1.5 per 1.000 live births (2).

Various etiological factors including ligamentous laxity, prenatal positioning, postnatal positioning, and racial predilection may lead to DDH (2). Hormonal, genetic and environmental factors have been described in the etiology. $\mathrm{DDH}$ in a first-degree relative, breech presentation, swaddling, and congenital calcaneovalgus foot deformities were identified as the strongest risk factors in DDH, whereas female sex, coexistence of torticollis and being the firstborn child were associated with having weaker effects on DDH (3).

The hip joint should be evaluated during routine examination of the newborn.

Ultrasonography is the most reliable imaging method for the diagnosis of DDH before femoral head epiphyseal nucleus ossification. The aim of the treatment is to maintain the normal relationship between the femoral head and the acetabulum and to sustain the reduction until the pathological changes are over.

The purpose of our study is to examine those risk factors leading to DDH and to assess the diagnostic value of hip ultrasonography.

\section{Material and Methods}

In our hospital, 9.102 imagings of hip ultrasonography data performed between January 2012 and January 2013 from 4.551 babies were retrospectively analyzed. The records of 170 babies, diagnosed with DDH, were obtained from our hospital registration system.

ToshibaAplio 800, ToshibaAplio 500, General ElectricsLogiq S6 brand ultrasonography devices and 11 $\mathrm{MHz}$ linear probes were used for the ultrasonographic examination of the hip. Ultrasonographic classification of the hip joint was performed according to the Graf method $(2,4)$.

Type I: alpha angle: $>60^{\circ}$ beta angle: $<55^{\circ}$,

Type Ila: alpha angle: $50^{\circ}-59^{\circ}$ beta angle: $>55^{\circ}$ (less than 3 months),

Type IIb: alpha angle: $50^{\circ}-59^{\circ}$ beta angle: $>55^{\circ}$ (greater than 3 months),

Type Ilc: alpha angle: $43^{\circ}-49^{\circ}$ beta angle: $<77^{\circ}$,

Type D: alpha angle: $43^{\circ}-49^{\circ}$ beta angle: $>77^{\circ}$,

Type IIla: alpha angle: $<43^{\circ}$ beta angle: $>77^{\circ}$ (hypoechoic cartilage acetabular roof),

Type IIIb: alpha angle: $<43^{\circ}$ beta angle: $>77^{\circ}$ (hyperechoic cartilage acetabular roof),
Type IV: alpha angle: $<43^{\circ}$ beta angle: $>77^{\circ}$ (Pressed downwards, perichondrium is horizontal or dips caudally).

The physical examination findings of patients were evaluated in terms of 'pili asymmetry' and 'limited abduction'. Interviews were held via telephone with the parents to evaluate the follow-up. Data on birth order, sex, type of delivery, gestational age, birth weight, oligohydramnios, multiple pregnancy, breech presentation, swaddling, family history, and foot anomalies were obtained from the hospital registry system and family interviews. In order to determine the relationship between risk factors and DDH, 170 control cases were randomly selected from those infants who underwent hip ultrasonography between January 2012 and January 2013 in our hospital. The control group were questioned concerning the presence of risk factors of DDH and the information was recorded.

Ethics committee approval was received for this study from the Ethics Committee of Ankara Keçiören Training and Research Hospital (25.01.2017/1301). Verbal informed consent was obtained prior to the interviews.

\section{Statistically Analysis}

Statistical analyzes were performed using the SPSS for Windows Version 22.0 package program. Categorical variables were compared by chi-square or Fisher's exact test. The significance level was taken as $p<0.05$.

\section{Results}

The ultrasonographic findings of 9.102 hips of 4.551 cases, who underwent hip ultrasonography for screening, were examined. We identified a total of 170 cases of whom DDH was detected. Among them, follow-up data could not be obtained for 18 patients. Additionally, one patient was excluded because of the diagnosis of spinal muscular atrophy.

One hundred sixty-nine infants were accepted into this study giving a total of 338 hips. Of the total number of patients, 138 (81.7\%) were female and 31 (18.3\%) were male. Hip ultrasound examination was performed between the ages of 46 and 188 days ( $80.3 \pm 20.3$ days). DDH was detected right sided in 89 cases and left sided in 125 cases. In 45 cases, DDH was bilateral. Ultrasonographic type distribution of each hip (338 hips in total) revealed that 124 (36.7\%) were type la-b (normal), 16 (4.7\%) were type lla-, 133 (39.3\%) were type Ila+, 33 (9.8\%) were type IIb, 19 (5.6\%) were type IIc, 5 $(1.5 \%)$ were type $\mathrm{D}$, and $8(2.4 \%)$ were type IIla. Type IIIb and type IV hips were not detected in any cases (Table I). 
In order to evaluate the risk factors, we compared 170 cases constituting the control group with 151 cases who were diagnosed with $\mathrm{DDH}$. Eighty-seven $(51.2 \%)$ of the control cases were male, and $83(48.8 \%)$ were female. In the control group, hip ultrasound examination was performed between the ages of 54 and 108 days ( $73 \pm 9$ days).

On physical examination of those cases diagnosed with $\mathrm{DDH}$, limited abduction was noted in 22 cases (14.6\%) and pili asymmetry in 14 cases (9.3\%). Physical examination findings of 115 patients (76.1\%) were normal. All 7 patients with type IIla hips had limited abduction, indicating a significant difference. No significant relationship was found between the pili asymmetry and the hip types.

The risk factors commonly associated with DDH including birth order, sex, type of delivery, gestational age, birth weight, oligohydramnios, multiple pregnancy, breech presentation, swaddling, family history, and the existence of foot anomalies were explored. Among these factors, prematurity, oligohydramnios and a positive family history were demonstrated to have a statistically significant association with DDH. A total of 135 patients had at least one risk factor, of whom 103 cases had positive physical examination signs for DDH. The relation between hip types and risk factors is shown in table II and the effect of risk factors on DDH is summarized in table III.

Follow-up information revealed that 52 of the DDH cases were followed up without treatment, 73 were treated with Pavlik harness, 4 with abduction orthosis, 12 with both Pavlik harness and abduction orthosis, 4 with open reduction, 4 with closed reduction and 2 had an operation plan at the time of writing.

\section{Discussion}

DDH is an orthopedic problem which is a spectrum of disorders ranging from the instability of hip joint to

Table I. Ultrasonographic type distribution of all hips

\begin{tabular}{|c|c|c|c|c|c|c|}
\hline \multirow[b]{2}{*}{ Type } & \multicolumn{2}{|l|}{ Right hip } & \multicolumn{2}{|l|}{ Left hip } & \multirow{2}{*}{$\begin{array}{l}\text { All hips } \\
\text { Number }\end{array}$} & \multirow[b]{2}{*}{$\%$} \\
\hline & Number & $\%$ & Number & $\%$ & & \\
\hline la-b & 80 & 47.3 & 44 & 26 & 124 & 36.7 \\
\hline Ila- & 8 & 4.7 & 8 & 4.7 & 16 & 4.7 \\
\hline Ilat & 53 & 31.3 & 80 & 47.3 & 133 & 39.3 \\
\hline Ilb & 18 & 10.7 & 15 & 8.9 & 33 & 9.8 \\
\hline Ilc & 6 & 3.6 & 13 & 7.7 & 19 & 5.6 \\
\hline D & 2 & 1.2 & 3 & 1.8 & 5 & 1.5 \\
\hline Illa & 2 & 1.2 & 6 & 3.6 & 8 & 2.4 \\
\hline Total & 169 & 100 & 169 & 100 & 338 & 100 \\
\hline
\end{tabular}

Table II. The relation between hip types and risk factors

\begin{tabular}{|c|c|c|c|c|c|c|c|c|c|c|c|c|}
\hline \multirow[b]{2}{*}{ Risk Factors } & \multicolumn{2}{|c|}{ Type la-lb (normal) } & \multicolumn{2}{|c|}{ Type Ila } & \multicolumn{2}{|c|}{ Type IIb } & \multicolumn{2}{|c|}{ Type IIc } & \multicolumn{2}{|c|}{ Type D } & \multicolumn{2}{|c|}{ Type IIla } \\
\hline & $\mathbf{n}$ & $\%$ & $\mathbf{n}$ & $\%$ & $\mathbf{n}$ & $\%$ & $\mathbf{n}$ & $\%$ & $\mathbf{n}$ & $\%$ & $\mathbf{n}$ & $\%$ \\
\hline Firstborn & 75 & 44.1 & 50 & 47.6 & 8 & 32 & 5 & 45.5 & 2 & 66.7 & 3 & 42.9 \\
\hline Female sex & 83 & 48.8 & 86 & 81.9 & 21 & 84 & 10 & 90.9 & 0 & 0 & 6 & 85.7 \\
\hline Caesarean section & 83 & 48.8 & 44 & 41.9 & 17 & 68 & 5 & 45.5 & 3 & 100 & 6 & 85.7 \\
\hline Prematurity & 4 & 2.4 & 5 & 4.8 & 3 & 12 & 1 & 9.1 & 2 & 66.7 & 1 & 14.3 \\
\hline Oligohydramnios & 8 & 4.7 & 10 & 9.5 & 4 & 16 & 1 & 9.1 & 2 & 66.7 & 0 & 0 \\
\hline Multiple pregnancy & 2 & 1.2 & 4 & 3.8 & 1 & 4 & 1 & 9.1 & 1 & 33.3 & 0 & 0 \\
\hline Breech presentation & 6 & 3.5 & 11 & 10.5 & 1 & 4 & 1 & 9.1 & 1 & 33.3 & 0 & 0 \\
\hline Swaddling & 49 & 28.8 & 34 & 32.4 & 5 & 20 & 5 & 45.5 & 0 & 0 & 1 & 14.3 \\
\hline Family history & 14 & 8.2 & 27 & 25.7 & 4 & 16 & 4 & 36.4 & 0 & 0 & 3 & 42.9 \\
\hline Family history (First degree) & 2 & 1.2 & 8 & 7.6 & 1 & 4 & 2 & 18.2 & 0 & 0 & 1 & 14.3 \\
\hline Foot anomaly & 3 & 1.8 & 3 & 2.8 & 2 & 8 & 0 & 0 & 1 & 33.3 & 1 & 14.3 \\
\hline
\end{tabular}


Table III. Impact of risk factors on developmental dysplasia of the hip

\begin{tabular}{|l|l|l|l|l|l|}
\hline & \multicolumn{2}{l|}{ DDH group } & \multicolumn{2}{l|}{ Control group } \\
\hline Risk factors & $\mathbf{n}$ & $\mathbf{\%}$ & $\mathbf{n}$ & $\mathbf{\%}$ & $\mathbf{\text { }}$ \\
\hline Firstborn & 68 & 45 & 75 & 44.1 & 0.869 \\
\hline Firstborn girl & 49 & 32.5 & 40 & 23.5 & 0.075 \\
\hline Caesarean section & 75 & 49.7 & 83 & 48.8 & 0.880 \\
\hline Prematurity & 12 & 7.9 & 4 & 2.4 & 0.030 \\
\hline Oligohydramnios & 17 & 11.3 & 8 & 4.7 & 0.048 \\
\hline Multiple pregnancy & 7 & 4.6 & 2 & 1.2 & 0.089 \\
\hline Breech presentation & 14 & 9.3 & 7 & 4.1 & 0.101 \\
\hline Swaddling & 45 & 29.8 & 49 & 28.8 & 0.848 \\
\hline Family history & 38 & 25.2 & 14 & 8.2 & 0.000 \\
\hline Family history (First degree) & 12 & 7.9 & 2 & 1.2 & 0.007 \\
\hline Foot anomaly & 7 & 4.6 & 3 & 1.8 & 0.199 \\
\hline DDH: Developmental dysplasia of the hip & & & & \\
\hline
\end{tabular}

total dislocation. DDH is a common deformity among the musculoskeletal system abnormalities and successful outcomes can be obtained with early diagnosis and intervention. If not treated early, the cost of treatment and the need for surgery increases exponentially and the chances of success decline (5).

The incidence of DDH has been reported to be between $0.08 \%$ and $5.2 \%$ in previous studies (6-8). The estimated prevalence of $\mathrm{DDH}$ in Turkey ranges between $0.5 \%$ and $1.5 \%(6)$. The incidence determined by hip ultrasonography screening ranges between $0.86 \%$ and $17 \%$ (9-16). In our research, the frequency of DDH was found to be $3.71 \%$.

All newborn infants should be examined for DDH during routine examination. $\mathrm{DDH}$ in the neonatal period can be diagnosed by eliciting the Ortolani or Barlow sign. By the second month of life, other signs of DDH might become obvious, including limited abduction, asymmetry of thigh folds, Galeazzi sign and pistoning of the hip (2). We did not regard the Ortolani and Barlow tests because our patients had passed the neonatal period. The most reliable examination finding after the newborn period is limited abduction $(6,10,11)$. In our study, limited abduction was noted in $14.6 \%$ of infants.

Demirhan et al. (12) detected the ratio of the coexistence of abnormal ultrasonography and pathologic physical examination findings as $40 \%$ whereas the ratio of abnormal ultrasonography without clinical evidence was 60\%. In the study of Karapınar et al. (13), 15,000 babies were screened regarding physical examination findings and risk factors. Among them, 482 infants with positive physical examination findings and risk factors were assessed with hip ultrasonography and pathologic ultrasonographic findings were observed in 73 (15.1\%) cases. Bache et al. (17) reported that only $20 \%$ of those patients with abnormal ultrasound findings at 6 weeks of age were found to have unstable hips in the initial examination. Tönnis (18) stated that all newborns should be screened because many pathologies can be detected by ultrasonography rather than other clinical procedures. In our study, we observed that $76.1 \%$ of the patients did not display evidence of hip instability on physical examination. Furthermore, we did not find any clinical evidence on $74.7 \%$ of infants with dysplasia who required treatment. This suggests the necessity of ultrasonographic screening for DDH even if physical examination findings are normal.

Imaging methods, such as hip ultrasonography, plain pelvis radiography, computed tomography, magnetic resonance imaging, and arthrography, can be used for the diagnosis and monitoring of DDH (2). The specificity and sensitivity of hip ultrasonography in diagnosing $\mathrm{DDH}$ is over $90 \%(19,20)$. There are various opinions about the time of the screening and postnatal $6^{\text {th }}$ week is defined as a period in which minor transient anomalies of the hip may resolve spontaneously, and early detection of permanent anomalies can be provided (21). Barlow (22) suggested that $60 \%$ of unstable hips noted at birth resolved within the first week and $88 \%$ in two months. In our hospital, hip ultrasonography is applied as a routine screening program and is usually performed after the first two months of life.

The etiology of DDH is multifactorial, including mechanical structural, mechanical environmental, and 
genetic factors (2). In the study of Ömeroğlu et al. (10), infants who had at least one risk factor conducive to DDH were found to have a three times higher occurrence rate of DDH compared to those who did not carry any risk factors. In the same study, breech presentation and positive family history were determined to be the most common risk factors associated with DDH. The incidence of DDH was $27 \%$ in infants with at least one risk factor and $9 \%$ in infants without any risk factors. (10) In the study of Akman et al. (23), female gender, oligohydramnios, and swaddling were defined as risk factors for DDH. Uslu et al. (24) found that the frequency of hip immaturity among a group of patients exposed and unexposed to the risk factors at $25.2 \%$ and $9.9 \%$, respectively. The same study also indicated that the incidence of hip dysplasia was $5.29 \%$ in the risk group, whilst no hip dysplasia was encountered in the control group. Furthermore, they demonstrated a correlation between the number of risk parameters and the incidence of immature or dysplastic hips during the newborn period. According to a study by Çakır et al. (5), the most frequent risk factor was identified as being a firstborn girl, followed by breech presentation, multiple pregnancy, and oligohydramnios. Breech presentation, oligohydramnios, female sex, and primiparity were determined to be risk factors for DDH in the study of Chan et al. (25). The meta-analysis of De Hundt et al. (26) indicated that breech presentation, female sex, positive family history, and clicking hips at physical examination were the most potent risk factors for DDH. In our study, prematurity, oligohydramnios, and positive family history were confirmed as statistically significant risk factors. Birth order, being a firstborn, type of delivery, birth weight, multiple pregnancy, breech presentation, swaddling, and the presence of foot anomalies were not found to be statistically significant for $\mathrm{DDH}$.

In the literature, DDH is found to be 4-6 times more common among girls than boys $(17,27,28)$. In our study, the female/male ratio was $4.4 / 1$, which is consistent with the literature.

Delays in diagnosis and treatment resulting in sequelae increase the cost of treatment. Furthermore, total hip arthroplasty may be necessary owing to the development of coxarthrosis. This condition prolongs the treatment process and leads to serious labor force loss. In cases of early diagnosis and conservative treatment, the necessity of surgical treatment can be reduced. Therefore, hip ultrasonography has been included in the screening program and adopted as a health policy in various countries. In our country, within the national early diagnosis and treatment program for $\mathrm{DDH}$, it is aimed to perform a routine hip examination during the newborn period, identify high risk and clinically suspected groups and to initiate early and appropriate treatment (29). Additionally, in our hospital, hip ultrasonography is applied to all infants as a part of the routine screening program.

\section{Study Limitations}

The limitations of our study include the small number of patients and the presence of patients whose followup information was not available. Additionally, there is a possibility that the information received from the parents of the patients may be incorrect due to misremembering.

\section{Conclusion}

Hip joint evaluation with regard to DDH in each visit, careful follow-up of infants with risk factors and family education about the influence of swaddling are important measures to prevent the development of DDH. Awareness concerning DDH among health professionals and parents plays a key role in preventing this condition. Training of health personnel in the identification of those high-risk babies is required for the early diagnosis and treatment of DDH.

\section{Ethics}

Ethics Committee Approval: Ethics committee approval was received for this study from the Ethics Committee of Ankara Keçiören Training and Research Hospital (25.01.2017/1301).

Informed Consent: Verbal informed consent was obtained prior to the interviews.

Peer-review: Externally peer-reviewed.

\section{Authorship Contributions}

Surgical and Medical Practices: G.Ü.D., S.K., Concept: G.Ü.D., S.K., E.S., Design: G.Ü.D., Y.T.Y., U.O., Ş.B., Data Collection or Processing: E.S., U.O., Ş.B., Analysis or Interpretation: G.Ü.D., S.K., Ç.Ü., Y.T.Y., Literature Search: G.Ü.D.,U.O., Ş.B. E.S., Writing: G.Ü.D., E.S., S.K., Ç.Ü., Y.T.Y., U.O., Ş.B.

Conflict of Interest: No conflict of interest was declared by the authors.

Financial Disclosure: The authors declared that this study received no financial support.

\section{References}

1. Klisic P. Congenital dislocation of the hip: a misleading term. I Bone Joint Surg Br 1989;71:136.

2. Herring IA (editor). Developmental Dysplasia of the Hip. In: Tachdjian's Pediatric Orthopedics from the Texas Scottish Rite 
Hospital for Children. 5th edition. WB. Saunders Co. 2014, 483579.

3. Fitch R. Ultrasound for screening and management of developmental dysplasia of the Hip. N C Med I 2014;75:142-5.

4. Graf R. The diagnosis of congenital hip-joint dislocation by the ultrasonic Combound treatment. Arch Orthop Trauma Surg 1980;97:117-33.

5. Çakır Çuhacı B, Kibar AE, Çakır HT, Arhan E, Cansu A, Yakut Hi. Ultrasonographic examination of developmental dysplasia of the hip in 300 infants. Turkish / Pediatr Dis 2009;3:5-9.

6. Tümer $Y$, Ömeroğlu H. Prevention of developmental hip dysplasia in Turkey. Acta Orthop Traumatol Turc 1997;31:176-81.

7. Mitchell GP. Problems in the early diagnosis and management of congenital dislocation of the hip. I Bone Joint Surg $\mathrm{Br}$ 1972;54:4-12.

8. Wilkinson JA. A post-natal survey for congenital displacement of the hip. J Bone Joint Surg Br 1972;54:40-9.

9. Doğruel H, Atalar H, Yavuz OY, Uraş I, Günay C, Şaylı U. An Evaluation of Developmental Hip Dysplasia Frequency and Screening Programs in Turkey: Review Turkiye Klinikleri I Med Sci 2008;28:357-60.

10. Ömeroğlu H, Koparal S. The role of clinical examination and risk factors in the diagnosis of developmental dysplasia of the hip: a prospective study in 188 referred young infants. Arch Orthop Trauma Surg 2001;121:7-11.

11. Köse N, Ömeroğlu H, Özyurt B, et al. Our three-year experience with an ultrasonographic hip screening program conducted in infants at 3 to 4 weeks of age. Acta Orthop Traumatol Turc 2006;40:285-90.

12. Demirhan $M$, Şar C, Aydınok HÇ, Çakmak $M$, Çoban A. Ultrasonography in the Diagnosis of Congenital Dislocation of the Hip (Is Newborn Screening Necessary?) Acta Orthop Traumatol Turc 1994;28:8-14.

13. Karapınar L, Öztürk H, Sürenkök F, Us MR. Evaluation of results of an orthopaedic screening program of 15.000 newborns. Joint Dis Rel Surg 2001;12:139-43.

14. Dogruel H, Atalar H, Yavuz OY, Sayli U. Clinical examination versus ultrasonography in detecting developmental dysplasia of the hip. Int Orthop 2008;32:415-9.

15. Okur A, Nakışlar F, Karsan O, Alparslan B. The value of ultrasound examination in the diagnosis and screening for congenital dislocation of the hip. Acta Orthop Traumatol Turc 1996;30:107-12
16. Söyüncü $Y$, Özdemir $H, A$ kyıldız $F F$, Ürgüden $M$, Altınel $E$. Searching of developmental dysplasia of hip in Antalya and surrounding. Acta Orthop Traumatol Turc 1999;33:105-9.

17. Bache CE, Clegg J, Herron M. Risk factors for developmental dysplasia of the hip: ultrasonographic findings in the neonatal period. J Pediatr Orthop B 2002;11:212-8.

18. Tönnis $D$, Storch $K$, Ulbrich $H$. Results of newborn screening for $\mathrm{CDH}$ with and without sonography and correlation of risk factors. J Pediatr Orthop 1990;10:145-52.

19. Rosenberg N, Bialik V, Norman D, Blazer S. The importance of combined clinical and sonographic examination of instability of the neonatal hip. Int Orthop 1998;22:185-8.

20. Lowry CA, Donoghue VB, Murphy JF. Auditing hip ultrasound screening of infants at increased risk of developmental dysplasia of the hip. Arch Dis Child 2005;90:579-81.

21. Harcke HT, Kumar SJ. The role of ultrasound in the diagnosis and management of congenital dislocation and dysplasia of the hip. J Bone Joint Surg Am 1991;73:622-8.

22. Barlow T. Early diagnosis and treatment of congenital dislocation of the hip. I Bone Joint Surg 1962;44-B:292-301.

23. Akman A, Korkmaz A, Aksoy MC, Yazıcı M, Yurdakök M, Tekinalp G. Evaluation of risk factors in developmental dysplasia of the hip: results of infantile hip ultrasonography. Turk I Pediatr 2007;49:290-4.

24. Uslu HS, Karatekin G, Uslu A, Kadığlu A, Nuhoğlu A. Evaluation of risk factors for developmental dysplasia of the hip in neonatal period. T Klin J Pediatr 2002;11:139-43.

25. Chan A, McCaul KA, Cundy PJ, Haan EA, Byron-Scott R. Perinatal risk factors for developmental dysplasia of the hip. Arch Dis Child 1997;76:94-100.

26. de Hundt M, Vlemmix F, Bais JMJ, et al. Risk factors for developmental dysplasia of the hip: a meta-analysis. Eur J Obstet Gynecol Reprod 2012;165:8-17.

27. Dunn PM. Perinatal observations on the etiology of congenital dislocation of the hip. Clin Orthop Relat Res 1976;119:11-22.

28. Clausen I, Nielsen KT. Breech position, delivery route and congenital hip dislocation. Acta Obstet Gynecol Scand 1988;67:595-7.

29. Köse N, Ömeroğlu H, Dağlar B. Gelişimsel Kalça Displazisi Ulusal Erken Tanı ve Tedavi Programı 2013. 